•研究报告・

\title{
雾灵山国家级自然保护区大型真菌物种多样性
}

\author{
杨苗 ${ }^{1}$, 张杰 $^{1}$ ，白嘉伟 ${ }^{1}$, 郭建刚 ${ }^{2}$ ，曲亚辉 ${ }^{2}$, 李会平 ${ }^{1,3^{*}}$
}

1. 河北农业大学林学院，河北保定 071000；2. 河北雾灵山国家级自然保护区管理中心，河北承德 067300; 3. 河北省城市森林健康技术创 新中心, 河北保定 071000

摘要: 大型真菌在维持生态系统稳定和为人类提供经济价值方面都具有重要作用, 本文对雾灵山国家级自然保护区中的大 型真菌资源进行了详细调查，为该保护区大型真菌资源开发和利用提供基础资料。作者于2019-2020年采用样线法和随机踏 查法对该保护区大型真菌物种资源多样性进行了初步调查和评估，共采集大型真菌标本1,132份。结合形态学和ITS序列证据 进行了鉴定，并通过查阅相关文献资料对该保护区大型真菌物种资源价值进行了评价。结果表明：雾灵山国家级自然保护区 共有236种大型真菌，隶属于2门6纲18目56科107属，其中15种属于子囊菌门，221种属于担子菌门。为方便统计，将大于等于 10 个种的科定为优势科，大于等于 5 个种的属定为优势属。其中优势科有红菇科、蘑菇科、多孔菌科和丝膜菌科，每个科所包 含的种数分别占总种数的 $8.90 \% 、 7.20 \% 、 5.93 \%$ 和 $4.24 \%$, 共计 62 种。优势属有红菇属(Russula)、蘑菇属(Agaricus)、我高菌 属(Amanita)、丝膜菌属(Cortinarius)、马勃属(Lycoperdon)、小皮伞属(Marasmius)等11个属, 共包含79个种，占总种数的 $33.48 \%$ 。对大型真菌的资源价值评价的结果显示，保护区内共有食用菌66种、药用菌35种、有毒菌36种和食药兼用菌26种。 研究结果表明, 雾灵山国家级自然保护区大型真菌资源丰富, 优势科和优势属中最为丰富的分别是红菇科和红菇属 (Russula), 具有经济价值的菌达127种，为食用菌的引种驯化、药用菌开发利用亦或有毒菌鉴别提供了丰富资源。

关键词: 雾灵山; 大型真菌; 物种多样性; 优势科属; 应用价值

杨苗, 张杰, 白嘉伟, 郭建刚, 曲亚辉, 李会平 (2021) 雾灵山国家级自然保护区大型真菌物种多样性. 生物多样性, 29, 1229-1235. doi: 10.17520/ biods.2021020.

Yang M, Zhang J, Bai JW, Guo JG, Qu YH, Li HP (2021) Species diversity of macrofungi in the Wuling Mountain National Nature Reserve. Biodiversity Science, 29, 1229-1235. doi: 10.17520/biods.2021020.

\section{Species diversity of macrofungi in the Wuling Mountain National Nature Reserve}

\author{
Miao Yang ${ }^{1}$, Jie Zhang ${ }^{1}$, Jiawei Bai ${ }^{1}$, Jiangang Guo ${ }^{2}$, Yahui $\mathrm{Qu}^{2}$, Huiping $\mathrm{Li}^{1,3^{*}}$ \\ 1 College of Forestry, Hebei Agricultural University, Baoding, Hebei 071000 \\ 2 Wuling Mountain National Nature Reserve Management Center, Chengde, Hebei 067300 \\ 3 Hebei Urban Forest Health Technology Innovation Center, Baoding, Hebei 071000
}

\begin{abstract}
Aims: Macrofungi plays a vital role in maintaining the stability of ecosystem and making unique and vital contributions to human economy. In order to provide basic information for the development and utilization of macrofungi, a detailed investigation of the macrofungi resources in the Wuling Mountain National Nature Reserve was carried out.

Methods: A preliminary survey and assessment of the macrofungal species diversity in the reserve was conducted between 2019 and 2020 using methods of line-transect surveys and random investigation. Totally, 1,132 specimens of macrofungi were collected. The diversity was analyzed based on morphological data and ITS evidence, and its resource value was evaluated by referring to relevant scientific literature.

Results: A total of 236 species of macrofungi were indentified in Wuling Mountain National Nature Reserve, belonging to 107 genera, 56 families, 18 orders, 6 classes, and 2 phyla. Of these, 15 species are classified as Ascomycota, and 221 species as Basidiomycota. For the convenience of statistics, families with more than ten species were defined as dominant families, and genera with more than five species were defined as dominant genera. The dominant families consisting of 62 species are Russulaceae, Agaricaceae, Polyporaceae, and Cortinariaceae. The number of species
\end{abstract}

收稿日期: 2021-01-14; 接受日期: 2021-04-12

基金项目: 河北雾灵山国家级自然保护区管理局资助项目(LX181102)

* 通讯作者 Author for correspondence. E-mail: 805737255@qq.com 
contained in each family account for $8.90 \%, 7.20 \%, 5.93 \%$ and $4.24 \%$ of the total number of species, respectively. Eleven fungal genera are dominant, such as Russula, Agaricus, Amanita, Cortinarius, Lycoperdon, and Marasmius. These genera consist of 79 species, accounting for $33.48 \%$ of the total species. The results of the evaluation of the resource value of macrofungi showed that there are 66 edible, 35 medicinal, 36 poisonous, and 26 both edible and medicinal species in the reserve.

Conclusion: The reserve is rich in macrofungal resources. The richest dominant families and dominant genera are Russulaceae and Russula. There are 127 species of valuable fungi. Meanwhile, the results provides rich resources for the introduction and domestication of edible fungi, the development and utilization of medicinal fungi, as well as the identification of toxic fungi.

Key words: Wuling Mountain; macrofungi; species diversity; dominant family and genera; application value

大型真菌是生物多样性的重要组成部分, 在生 态系统中起到物质转化和能量流动的作用。我国对 于大型真菌的利用有着悠久的历史, 新中国成立以 后, 越来越多的菌物研究者对我国各地的菌物资源 进行了专业考察。在我国华北地区, 菌物研究学者 们调查了内蒙古罕山国家级自然保护区(王雪珊等, 2020)、内蒙古大青沟自然保护区(图力古尔和李玉, 2000)、大小兴安岭地区大型真菌的多样性(图力古 尔等, 2019), 并从物种组成、区系特点、与植物群 落相关性以及生态系统多样性等方面研究了大型 真菌的特点。卢维来等(2015)对北京地区大型真菌 进行了整理分析, 共整理得到 867 种; 吴记贵等 (2020)调查了北京松山国家级自然保护区中有毒真 菌的种类。而对于河北省大型真菌资源相关研究报 道少之又少。王谦等(2005)调查了雾灵山地区野生 食药用真菌, 共发现野生食药用菌72种; 李洁 ${ }^{11}$ 调 查了河北省太行山地区大型真菌的种类及生态分 布, 共采集到大型真菌145种。当前对雾灵山自然保 护区野生大型真菌的资源调查和经济价值相关报 道比较少。

本研究通过在2019-2020年对雾灵山国家级自 然保护区大型真菌资源的调查, 详细分析了其优势 科属及经济价值, 以促进该地区大型真菌资源的保 护、合理开发和利用，同时对该地区的菌物物种多 样性进行补充。

\section{材料与方法}

\section{1 研究区概况}

雾灵山国家级自然保护区位于河北省兴隆县 境内, 地处 $117^{\circ} 17^{\prime}-117^{\circ} 35^{\prime}$ E、 $40^{\circ} 29^{\prime}-40^{\circ} 36^{\prime} \mathrm{N}$ 之间,

(1) 李洁 (2010) 河北省太行山区野生高等真菌资源调查及四种子实体 抗氧化活性研究. 硕士学位论文, 河北师范大学, 石家庄.
总面积 1,4310.2 ha, 海拔 800-1,900 m, 顶峰海拔 2,118 m (张建华等, 2014)。雾灵山森林覆盖率达 $80 \%$, 属温带湿润大陆季风性气候, 年均降水量达 700 多毫米。雾灵山因处于暖温带落叶阔叶林带向 温带针阔混交林的过渡地带, 同时是华北、东北和 内蒙古三大植物区系交汇区域, 造就了植被类型的 多样化和大型真菌种类的多样化。保护区的主要树 种有山杨 (Populus davidiana)、蒙古栋(Quercus mongolica) 、华北落叶松 (Larix principisrupprechtii)、胡桃楸(Juglans mandshurica)、油松 (Pinus tabuliformis)、白桦(Betula platyphylla)、五角 枫(Acer mono)等。该区域的土壤主要为盐基不饱和 的弱酸性森林土, $\mathrm{pH}$ 值介于5.5-6.5之间, 为大型真 菌的生长提供了很好的土壤条件。

\section{2 调查路线}

野外调查根据该保护区生物多样性分布、大型 真菌资源普遍分布规律、地形地貌和交通可达性确 定调查区域、采样路线(图1)。采集时间为大量出菌 时期, 主要为2019年和2020年的7、8、9三个月份。 主要有四条路线: 第一条从保护区南门沿十八潭旅 游线路到仙人塔; 第二条从保护区南门经凌云度假 村到娘娘洼沟; 第三条从保护区南门到在水一方景 点、木碗沟、前五岔沟, 最后到后五岔沟; 第四条 从保护区南门经怡然亭、林海云天观景亭、莲花池、 主峰、拇指峰、龙潭、大坑、清凉界碑, 最后至景 区北门。调查范围包括主要线路附近人可到达的区 域。

\section{3 标本采集和制作}

在采集大型真菌子实体的过程中, 记录其地理 位置、生态环境、大小、颜色、附着物等形态特征。 同时用高清相机进行拍摄, 拍摄时保证子实体的完 整性，一张照片展示子实体的多个面。小心采集子 


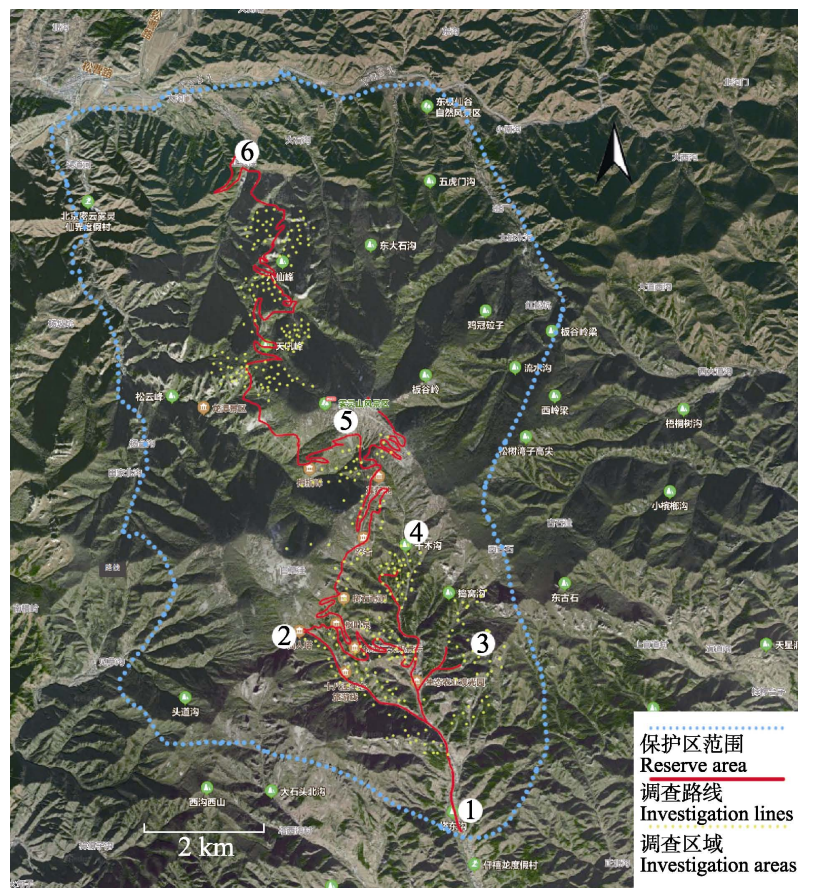

图1 雾灵山国家级自然保护区大型真菌调查线路。(1)保护 区南门; (2)仙人塔; (3)娘娘洼沟; (4)五岔沟; (5)莲花池; (6)保 护区北门。

Fig. 1 Investigation lines of macrofungi in the Wuling Mountain National Nature Reserve. (1) South gate of the reserve; (2) Fairy Tower; (3) Niangniangwa Valley; (4) Wucha Valley; (5) Lianhuachi; (6) North gate of the reserve.

实体, 生于地上的用刮皮刀挖取, 生于立木上的用 锯将子实体相邻木段切下, 保证菌体完整, 对子实 体进行编号装到塑料盒中。本次调查共采集大型真 菌标本 1,132 份, 采集后, 经烘箱 $40^{\circ} \mathrm{C}$ 烘干, 用于标 本制作及后期DNA提取和分子鉴定。贴好标签的标 本均存放于雾灵山国家级自然保护区标本室。

\section{4 大型真菌标本鉴定}

大型真菌的鉴定采用传统形态学鉴定和DNA 序列比对相结合的方式, 并参考相关文献资料(卯 晓岗, 2000; 袁明生和孙佩琼, 2013; 李玉等, 2015; 邵力平和项存悌, 2017; 图力古尔, 2018)。传统形态 研究既包括观察菌盖、菌褶、菌管、菌环、菌柄、 菌托的形态和狍子印的颜色等, 也包括对标本进行 徒手切片、在显微镜下观察成熟孢子和囊状体等形 态特征。对于部分疑难种采用DNA序列分析法进行 鉴定。

DNA的提取采用CTAB法。使用真菌通用引物 ITS-1/ITS-4对标本进行PCR扩增, 扩增产物送北京 华大基因研究中心有限公司进行测序, 测序结果通 过比对NCBI数据库中的ITS序列结果再结合子实体
形态特征进行鉴定。拉丁名参照真菌拉丁名命名网 址(http://www.indexfungorum.org/)公布的名称。

\section{5 统计分析}

大型真菌的物种组成根据研究区域所采集的 标本数据在Excel中进行科、属的统计分析, 统计物 种数目及其所占比例。将科内包含 10 种及以上的科 定为优势科, 将属内含 5 种及以上的属定为优势属 (王雪珊等, 2020)。食用菌、药用菌、毒菌的划分参 考戴玉成和杨祝良(2008)、戴玉成等(2010)、图力古 尔(2014)及Wu (2019)等。

\section{结果}

\section{1 大型真菌的种类组成}

该保护区大型真菌种类丰富, 经调查统计, 共 计2门6纲18目56科107属236种, 其中子囊菌门3纲4 目9科11属15种, 所包含种数占总种数的 $6.36 \%$ 。担 子菌门 3 纲 14 目 47 科 96 属 221 种, 所包含种数占总种 数的 $93.64 \%$ 。

在236种中, 经形态学鉴定和ITS序列分析, 共 发现 6 种中国新记录种, 分别为 Agaricus cordillerensis Kerrigan、A. gemellatus Kerrigan, et al. Cortinarius falsosus Moënne-Locc. \& Reumaux 、 Hygrocybe singeri (A. H. Sm. \& Hesler) Singer、 Pluteus roseipes Höhn和Lactarius cremicolor H. Lee, et al. 。

\section{2 大型真菌优势科属统计}

雾灵山保护区大型真菌科属种的数量统计见 表1，优势属见表2。

雾灵山保护区的大型真菌优势科 $(\geq 10$ 种)共有 4 科, 即红菇科、蘑菇科、多孔菌科和丝膜菌科, 分 别占总种数的 $8.90 \% 、 7.20 \% 、 5.93 \%$ 和 $4.24 \%$ 。优势 科包含的种数共占总种数的 $26.27 \%$ 。结合表 1 显示, 含有 1 种的有 19 科, 占总科数的 $33.93 \%$; 含有 $2-5$ 种 的有 26 科, 占总科数的 $46.43 \%$; 含 $6-9$ 种的有 7 科, 占总科数的 $12.50 \%$ 。综合来看, 含有 $2-5$ 种的科占大 多数, 优势科虽然占总科数的比例不大, 但种数多, 占四成以上, 有很好的研究开发价值。

该保护区的优势属 $(\geq 5$ 种)共有11属(表2), 主要 有蘑菇属(Agaricus)、红菇属(Russula)、乳菇属 (Lactarius)、丝膜菌属(Cortinarius)、我膏菌属 (Amanita)、侧 属(Pleurotus)等, 优势属占总属数的 $10.28 \%$, 包含的种共有 79 种, 占总种数的 $33.47 \%$ 。 
表1 雾灵山国家级自然保护区大型真菌的科、属、种数量统计

Table 1 Number of families, genera and species of macrofungi in Wuling Mountain National Nature Reserve

\begin{tabular}{|c|c|c|c|c|c|}
\hline 科 Family & $\begin{array}{l}\text { 属数 } \\
\text { No. of genera }\end{array}$ & $\begin{array}{l}\text { 种数 } \\
\text { No. of species }\end{array}$ & 科 Family & $\begin{array}{l}\text { 属数 } \\
\text { No. of genera }\end{array}$ & $\begin{array}{l}\text { 种数 } \\
\text { No. of species }\end{array}$ \\
\hline 绿杯盘菌科 Chlorociboriaceae & 1 & 1 & 球盖菇科 Strophariaceae & 4 & 6 \\
\hline 地锤菌科 Cudoniaceae & 1 & 1 & 口蘑科 Tricholomataceae & 2 & 4 \\
\hline 马鞍菌科 Helvellaceae & 1 & 4 & 木耳科 Auriculariaceae & 1 & 1 \\
\hline 羊肚菌科 Morchellaceae & 1 & 1 & 牛肝菌科 Boletaceae & 3 & 7 \\
\hline 盘菌科 Pezizaceae & 1 & 2 & 钟钉菇科 Gomphidiaceae & 1 & 1 \\
\hline 火丝盘菌科 Pyronemataceae & 3 & 3 & 硬皮马勃科 Sclerodermataceae & 1 & 1 \\
\hline 肉杯菌科 Sarcoscyphaceae & 1 & 1 & 黍盖牛肝菌科 Suillaceae & 1 & 3 \\
\hline 疮杯盘菌科 Tarzettaceae & 1 & 1 & 桩菇科 Paxillaceae & 1 & 4 \\
\hline 炭球菌科 Hypoxylaceae & 1 & 1 & 齿菌科 Hydnaceae & 4 & 5 \\
\hline 蘑菇科 Agaricaceae & 5 & 17 & 地星科 Geastraceae & 1 & 4 \\
\hline 鹅膏菌科 Amanitaceae & 1 & 6 & 钉菇科 Gomphaceae & 1 & 3 \\
\hline 碘伏革菌科 Amylocorticiaceae & 1 & 1 & 刺革菌科 Hymenochaetaceae & 2 & 3 \\
\hline 珊瑚菌科 Clavariaceae & 1 & 1 & 蘚菇科 Rickenellaceae & 1 & 1 \\
\hline 丝膜菌科 Cortinariaceae & 1 & 10 & 革菌科 Thelephoraceae & 1 & 2 \\
\hline 锈耳科 Crepidotaceae & 1 & 3 & 鬼笔科 Phallaceae & 2 & 2 \\
\hline 粉禇菌科 Entolomataceae & 2 & 4 & 拟层孔菌科 Fomitopsidaceae & 1 & 1 \\
\hline 轴腹菌科 Hydnangiaceae & 1 & 3 & 干皮菌科 Incrustoporiaceae & 1 & 1 \\
\hline 蜡伞科 Hygrophoraceae & 2 & 4 & 耙齿菌科 Irpicaceae & 1 & 1 \\
\hline 层腹菌科 Hymenogastraceae & 1 & 2 & 硫磺菌科 Laetiporaceae & 2 & 2 \\
\hline 丝盖伞科 Inocybaceae & 1 & 5 & 平革菌科 Phanerochaetaceae & 1 & 1 \\
\hline 马勃科 Lycoperdaceae & 2 & 6 & 多孔菌科 Polyporaceae & 8 & 14 \\
\hline 小皮伞科 Marasmiaceae & 1 & 5 & 齿耳菌科 Steccherinaceae & 1 & 1 \\
\hline 小菇科 Mycenaceae & 2 & 6 & 红菇科 Russulaceae & 2 & 21 \\
\hline 光茸菌科 Omphalotaceae & 2 & 5 & 㓞革菌科 Stereaceae & 2 & 4 \\
\hline 膨瑚菌科 Physalacriaceae & 3 & 5 & 耳匙菌科 Auriscalpiaceae & 1 & 1 \\
\hline 侧耳科 Pleurotaceae & 1 & 5 & 花耳科 Dacrymycetaceae & 2 & 2 \\
\hline 光柄菇科 Pluteaceae & 1 & 7 & 银耳科 Tremellaceae & 1 & 2 \\
\hline 小脆柄菇科 Psathyrellaceae & 3 & 6 & 未定科 Incertae sedis & 14 & 21 \\
\hline 裂褶菌科 Schizophyllaceae & 1 & 1 & 总计 Total & 107 & 236 \\
\hline
\end{tabular}

加粗字体表示优势科 Bold font indicates the dominant families

优势属所包含种较多, 在该地区大型真菌物种中占 主导地位。

\section{3 雾灵山国家级自然保护区大型真菌资源评价} 经调查和查阅相关文献, 将该保护区大型真菌 资源分为食用菌、药用菌、食药兼用菌、有毒和应 用价值不明五类。其中食用菌共有 66 种, 占总种数 的 $27.97 \%$; 药用菌共有 35 种, 占总种数的 $14.83 \%$; 食药兼用菌共 26 种, 占总种数的 $11.02 \%$; 毒菌36种, 占总种数的 $15.25 \%$; 还有 73 种大型真菌的应用价值 不明。统计得出, 有经济价值的大型真菌共有 127 种，对该保护区具有很好的利用开发价值。

\subsection{1 食用菌}

调查结果显示, 雾灵山国家级自然保护区野生 食用菌共有 66 种。其中常见的种有地匙菌 (Spathularia flavida)、棱柄马鞍菌(Helvella lacunosa)、白杵磨菇(Agaricus osecanus)、赫鳞蘑菇 (A. subrufescens)、球基蘑菇(A. abruptibulbus)、红蜡 蘑(Laccaria laccata)、梭狍环柄菇 (Lepiota magnispora)、红菇蜡伞(Hygrophorus russula)、大盖 小皮伞(Marasmius maximus)、白黄侧耳(Pleurotus cornucopiae)、凤尾菇(P. pulmonarius)、柠檬鳞伞 (Pholiota limonella)、趐鳞伞(P. squarrosa)、油口磨 
表2 雾灵山国家级自然保护区大型真菌优势属 $(\geq 5$ 种)

Table 2 Dominant genera of macrofungi in Wuling Mountain National Nature Reserve ( $\geq 5$ species)

\begin{tabular}{llll}
\hline $\begin{array}{l}\text { 属 } \\
\text { Genus }\end{array}$ & $\begin{array}{l}\text { 种数 } \\
\text { No. species } \%\end{array}$ & $\begin{array}{l}\text { 占总种数比例 } \\
\text { 营养类型 } \\
\text { Nutritional type }\end{array}$ \\
\hline 红菇属 Russula & 12 & 5.08 & 共生 Symbiotic \\
蘑菇属 Agaricus & 10 & 4.24 & 土生 Geophilous \\
丝膜菌属 Cortinarius & 10 & 4.24 & 共生 Symbiotic \\
乳菇属 Lactarius & 9 & 3.81 & 共生 Symbiotic \\
光柄菇属 Pluteus & 7 & 2.97 & 木生 Lignicolous \\
我亳菌属 Amanita & 6 & 2.54 & 共生 Symbiotic \\
马勃属 Lycoperdon & 5 & 2.12 & 土生 Geophilous \\
小皮伞属 Marasmius & 5 & 2.12 & 土生 Geophilous \\
小菇属 Mycena & 5 & 2.12 & 木生、土生 \\
& & & Lignicolous \& \\
geophilous \\
土生 Geophilous \\
丝盖伞属 Inocybe & 5 & 2.12 & 木生 Lignicolous \\
侧耳属 Pleurotus & 5 & 2.12 & \\
共计 Total & 79 & 33.47 & \\
\hline
\end{tabular}

(Tricholoma flavovirens)、鸡 油菌 (Cantharellus cibarius)、灰喇叭菌(Craterellus cornucopioides)、芥 黄蜜环菌(Armillaria sinapina)、桂花耳(Dacryopinax spathularia)、银盖口蘑(Tricholoma argyraceum)、橙 黄疮柄牛肝菌(Leccinum aurantiacum)等(卯晓岗, 2000; 戴玉成等, 2010; Wu et al, 2019)。

\subsection{2 药用菌}

经调查, 该保护区药用真菌共有35种。药用菌 可分为多种功效, 如抑制肿瘤作用的有田头菇 (Agrocybe praecox)、单色齿毛菌(Cerrena unicolor)、 掌状花耳(Dacrymyces palmatus)、三色拟迷孔菌 (Daedaleopsis tricolor)、木蹄层孔菌 (Fomes fomentarius)、红缘拟层孔菌(Fomitopsis pinicola)、 树舌灵芝 (Ganoderma applanatum)、松乳菇 (Lactarius deliciosus)、紫丁香蘑(Lepista nuda)、毛 韧革菌 (Stereum hirsutum)、毛革盖菌 (Trametes hirsuta) 等(卯晓岗, 1998; 戴玉成和图力古尔, 2007)。蜜环菌 (Armillaria mellea) 和芥黄蜜环菌可镇 静安神、增强免疫力、治疗神经衰弱、失眠等(戴玉 成和图力古尔, 2007)。消炎止血作用的有头状秃马 勃 (Calvatia craniiformis)、梨形马勃 (Lycoperdon pyriforme)、网纹马勃(L. perlatum)、白刺马勃 $(L$. wrightii)、毛嘴地星(Geastrum fimbriatum)、袋形地 星(G. saccatum)、鳞皮扇菇(Panellus stipticus)等(赵 会珍等, 2007)。益肠胃的如鸡油菌, 治疗神经性皮
炎的色钉菇(Chroogomphus rutilus), 可治疗胃病的 隆纹黑蛋巢菌(Cyathus striatus), 可治疗腰疼、血压 升高等症状的白齿耙菌(Irpex lacteus)等(卯晓岗, 2000; 戴玉成和杨祝良, 2008; Wu et al, 2019)。

部分野生大型真菌具有食药两种功能, 在该保 护区共发现26种。常见种有羊肚菌 (Morchella esculenta)、金针菇(Flammulina filiformis)、芥黄蜜 环菌、裂褶菌(Schizophyllum commune)、田头菇、 黄绿卷毛菇(Floccularia luteovirens)、紫丁香蘑、美 味牛肝菌(Boletus edulis)、色钉菇、淡色孔硫磺菌 (Laetiporus cremeiporus)、松乳菇、厚环黏盖牛肝菌 (Suillus grevillei)、茶耳(Tremella foliacea)、银耳(T. fuciformis)等(卯晓岗, 2000; 王谦等, 2005; Wu et al, 2019)。

\subsection{3 有毒菌}

经调查, 该保护区共有有毒菌36种。毒菌类型 主要有胃肠炎型、神经精神型和溶血型等。胃肠炎 型发病快、恢复快, 表现为恶心、呕吐、腹泻, 如 无并发症, 死亡者甚少, 此类型主要有黑胶耳 (Exidia glandulosa) 、晶粒鬼伞 (Coprinellus micaceus)、点柄黏盖牛肝菌(Suillus granulatus)、毒 红菇(Russula emetica)、病狍褐盘菌(Peziza badia)等 (图力古尔等, 2014; 陈作红等, 2016)。神经精神型 主要中毒表现有心率减慢、血压降低、恶心腹泻、 出汗、过度兴奋、头晕眼花、小人国幻觉等, 主要 有毒蝇鹅膏菌(Amanita muscaria)、球基鹅膏菌( A. subglobosa)、污白丝盖伞(Inocybe geophylla)、裂丝 盖伞(I. rimosa)、白霜杯伞(Clitocybe dealbata)、血 红小菇(Mycena haematopus)等(卯晓岗, 2006; 陈作 红等, 2016)。溶血型表现症状为恶心、呕吐、头痛 等, 主要有卷边桩菇(Paxillus involutus)、泡质盘菌 (Peziza vesiculosa)、褐环黏盖牛肝菌(Suillus luteus) 等(图力古尔等, 2014; 陈作红等, 2016)等。其他常 见毒蘑菇有毒粉褶菌(Entoloma sinuatum)、冠状环 柄菇 (Lepiota cristata)、长条棱鹅膏 (Amanita longistriata)、黄褐丝盖伞(Inocybe flavobrunnea)、可 爱红菇(Russula grata)等(包海鹰, 2006; 图力古尔等, 2014; Wu et al, 2019)。

\section{3 讨论}

调查共发现大型真菌236种, 其中包含6种中国 新记录种。优势科有红菇科、蘑菇科、多孔菌科和 
丝膜菌科, 优势属有蘑菇属、红菇属、乳菇属、丝 膜菌属等11个属。通过对雾灵山国家级自然保护区 与辽宁白狼山国家级自然保护区 ${ }^{\circledR}$ 、大青沟自然保 护区(图力古尔和李玉, 2000)及广西弄岗国家级自 然保护区 ${ }^{2}$ 的对比发现, 雾灵山保护区在大型真菌 组成上与白狼山保护区的亲缘关系最近, 除世界分 布属外共有属有23个, 这可能和两地地理位置相近, 同属于华北地区燕山山脉, 气候条件和植被类型相 似, 物种之间交流频繁有关。雾灵山和大青沟保护 区大型真菌组成相似性系数较白狼山偏低, 这可能 和气候、植被、林分组成存在差异有关。而和弄岗 保护区的大型真菌组成相似性更低, 主要由于弄岗 保护区为热带季风气候，气候不同导致植被类型、 土壤条件和物种多样性均存在较大差异。

在该地区大型真菌中，食用菌66种，药用菌35 种，食药兼用菌26种，有毒菌36种。王谦等(2005) 调查该地区的食药用真菌资源共发现72种，本次调 查对其进行了补充, 共发现55种此前没有被调查到 的食药用菌资源, 如羊肚菌、线柄裸脚伞(Gymnopus confluens)、凤尾菇、田头菇等。当地人主要采集牛 肝菌类和色钉菇, 对于其他具有食用价值的野生真 菌没有很好地利用和开发。除食用真菌外, 有毒真 菌也应该得到重视, 我国每年都有吃蘑菇而中毒的 事件发生。因此, 弄清毒蘑菇的种类和中毒类型, 对于预防和治疗具有重要意义。

经过 2 年时间的采集, 对该地区的大型真菌资 源进行了初步研究。但该地区环境复杂、地形多样、 海拔较高, 有一些区域很难涉足, 所以本次调查评 估不能够完全反映该地区大型真菌资源状况。今后 还需要对该地区的大型真菌资源进行不断的积累 完善, 研究菌物与其周围植被、土壤等可能存在的 相关性, 并对保护区内的濒危大型真菌物种进行评 估, 以便更好地保护该地区大型真菌的物种多样 性。

\section{参考文献}

Bao HY (2006) Studies on Chemical Compositions and Pharmacological Action of Some Toadstools. Inner Mongolia Education Press, Huhhot. (in Chinese) [包海鹰

(1) 高洋 (2017) 辽宁省白狼山国家级自然保护区大型真菌多样性研究 硕士学位论文, 吉林农业大学, 长春.

(2) 牟光福 (2019) 广西弄岗国家级自然保护区大型真菌资源调查与评

价. 硕士学位论文, 广西大学, 南宁.
(2006) 毒蘑菇化学成分与药理活性的研究. 内蒙古教育 出版社, 呼和浩特.]

Bau T (2018) Mushroom Taxonomy. Science Press, Beijing. (in Chinese) [图力古尔 (2018) 草菌分类学. 科学出版社, 北京.]

Bau T, Bao HY, Li Y (2014) A revised checklist of poisonous mushrooms in China. Mycosystema, 33, 517-548. (in Chinese with English abstract) [图力古尔, 包海鹰, 李玉 (2014) 中国毒蘑菇名录. 菌物学报, 33, 517-548.]

Bau T, Li Y (2000) Fungal community diversity in Daqinggou Nature Reserve. Acta Ecologica Sinica, 20, 986-991. (in Chinese with English abstract) [图力古尔, 李玉 (2000) 大 青沟自然保护区大型真菌群落多样性研究. 生态学报, 20, 986-991.]

Bau T, Li Y (2000) Study on fungal flora diversity in Daqinggou Nature Reserve. Chinese Biodiversity, 8, 73-80. (in Chinese with English abstract) [图力古尔, 李玉 (2000) 大青沟自然保护区大型真菌区系多样性的研究. 生物多 样性, 8, 73-80.]

Bau T, Wang XS, Zhang P (2019) Floristic of agarics and boletus in the Greater and Lesser Khinggan Mountains. Biodiversity Science, 27, 867-873. (in Chinese with English abstract) [图力古尔, 王雪珊, 张鹏 (2019) 大小兴安岭地 区伞菌和牛肝菌类区系. 生物多样性, 27, 867-873.]

Chen ZH, Yang ZL, Bau T, Li TH (2016) Poisonous Mushrooms: Recognition and Poisoning Treatment. Science Press, Beijing. (in Chinese) [陈作红, 杨祝良, 图力古尔, 李泰辉 (2016) 毒蘑菇识别与中毒防治. 科学出版社, 北 京.]

Dai YC, Bau T (2007) Illustrations of Edible and Medicinal Fungi in Northeastern China. Science Press, Beijing. (in Chinese with English abstract) [戴玉成, 图力古尔 (2007) 中国东北食药用真菌图志. 科学出版社, 北京.]

Dai YC, Yang ZL (2008) A revised checklist of medicinal fungi in China. Mycosystema, 27, 801-824. (in Chinese with English abstract) [戴玉成, 杨祝良 (2008) 中国药用 真菌名录及部分名称的修订. 菌物学报, 27, 801-824.]

Dai YC, Zhou LW, Yang ZL, Wen HA, Bau T, Li TH (2010) A revised checklist of edible fungi in China. Mycosystema, 29, 1-21. (in Chinese with English abstract) [戴玉成, 周丽伟, 杨祝良, 文华安, 图力古尔, 李泰辉 (2010) 中国食用菌 名录. 菌物学报, 29, 1-21.]

Li Y, Li TH, Yang ZL, Bau T, Dai YC (2015) Resources of Macrofungi in China. Central Plain Farmers Press, Zhengzhou. (in Chinese) [李玉, 李泰辉, 杨祝良, 图力古 尔, 戴玉成 (2015) 中国大型菌物资源图鉴. 中原农民出 版社, 郑州.]

Lu WL, Wei TZ, Wang XL, Li Y, Lü HM, Yang L, Yang WJ, Yao YJ (2015) Species diversity of macrofungi in Beijing, China. Mycosystema, 34, 982-995. (in Chinese with English abstract) [卢维来, 魏铁铮, 王晓亮, 李熠, 吕红梅, 杨柳, 杨文婧, 姚一建 (2015) 北京地区大型真菌多样性分析. 菌物学报, 34, 982-995.]

Mao XL (2000) Chinese Macrofungi. Henan Science and 
Technology Press, Zhengzhou. (in Chinese) [卯晓岗 (2000) 中国大型真菌. 河南科学技术出版社, 郑州.]

Mao XL (1998) Economic Fungi of China. Science Press, Beijing. (in Chinese) [卯晓岗 (1998) 中国经济真菌. 科学 出版社, 北京.]

Mao XL (2006) Poisonous mushrooms and their toxins in China. Mycosystema, 25, 345-363. (in Chinese with English abstract) [卯晓岗 (2006) 中国毒菌物种多样性及其毒素. 菌物学报, 25, 345-363.]

Shao LP, Xiang CD (2017) Forest Mushrooms in China. Northeast Forestry University Press, Harbin. (in Chinese) [邵力平, 项存悌 (2017) 中国森林蘑菇. 东北林业大学 出版社, 哈尔滨.]

Wang Q, Liu HX, Zhang JG, Lu J, Liu YX, Yang LH, Ji H, Chen WJ (2005) Investigation of wild edible and medical fungi of Wuling Mountain area. Journal of Hebei University (Natural Science Edition), 25, 523-525. (in Chinese with English abstract) [王谦, 刘会欣, 张俊刚, 卢婕, 刘玉霞, 杨立华, 冀宏, 陈文杰 (2005) 雾灵山地区野生食药用真 菌资源调查. 河北大学学报(自然科学版), 25, 523-525.]

Wang XS, Bau T, Bao JS, Bao H, Feng J (2020) Macrofungal diversity in Hanwula National Nature Reserve, Inner Mongolia. Mycosystema, 39, 695-706. (in Chinese with English abstract) [王雪珊, 图力古尔, 宝金山, 宝虎, 丰洁 (2020) 内蒙古罕山国家级自然保护区大型真菌多样性. 菌物学报, 39, 695-706.]

Wu F, Zhou LW, Yang ZL, Bau T, Li TH, Dai YC (2019) Resource diversity of Chinese macrofungi: Edible, medicinal and poisonous species. Fungal Diversity, 98, $1-76$.

Wu JG, Zhou H, Hou CL (2020) Diversity of poisonous macrofungi in Beijing Songshan National Nature Reserve. Journal of Capital Normal University (Natural Science Edition), 41(4), 52-56. (in Chinese with English abstract) [吴记贵, 周昊, 侯成林 (2020) 北京松山国家级自然保 护区有毒大型真菌物种多样性研究. 首都师范大学学报 (自然科学版), 41(4), 52-56.]

Yuan MS, Sun PQ (2013) Color Atlas of Large Fungus in China. Sichuan Science and Technology Press, Chengdu. (in Chinese) [袁明生, 孙佩琼 (2013) 中国大型真菌彩色图 谱. 四川科学技术出版社, 成都.]

Zhang JH, Yang XB, Lu SW, Bai CL, Tan HX (2014) Study on shrub-grass diversity and influence factors of different forests in Wuling Mountain of Hebei Province. Journal of Agricultural University of Hebei, 37, 27-32. (in Chinese with English abstract) [张建华, 杨新兵, 鲁绍伟, 白翠玲, 谭海霞 (2014) 河北雾灵山不同林分灌草多样性及影响 因素研究. 河北农业大学学报, 37, 27-32.]

Zhao HZ, Xu YY, Fu XY, Fan L (2007) The progress of food and medical values of puff-balls. Microbiology, 34, 367-369. (in Chinese with English abstract) [赵会珍, 胥艳 艳, 付晓燕, 范黎 (2007) 马勃的食药用价值及其研究进 展. 微生物学通报, 34, 367-369.]

(责任编委：郭良栋 责任编辑：时意专) 